\title{
MENDETEKSI PENGELAPAN DANA PERJALANAN DINAS DENGAN APLIKASI INTERNAL TICKETING SYSTEM
}

\author{
Kevin Christianto ${ }^{1}$, Deny ${ }^{2}$ \\ 1,2 Program Studi Sistem Informasi, Universitas Bunda Mulia Jakarta, Indonesia \\ E-mail : kevin.hikoza@gmail.com, deny.shaobin@gmail.com
}

Submission date: $2020-05-18$

Accepted date: 2020-06-09

\begin{abstract}
Employee official travel activities in a company have an important role in supporting business operations and developing the business wing of the company, especially for large companies that have many branch offices in various regions in Indonesia. With more and more official trips requiring official travel tickets, a system that can internally regulate how tickets are purchased and paid is needed. The system is needed to reduce unnecessary official travel activities and valid data to be compared with data from third-party systems in terms of payment of ticket reservations. Researchers conduct literature studies, interviews, and observations. Literature study conducted by researchers to find the concept of an appropriate methodology to develop the Internal Ticketing System application. Interviews are used to examine important input on the Internal Ticketing System application of several companies that have quite intensive business travel activities, so that they are suitable and useful to be implemented later in the field, and business observations are empowered by researchers to look directly at the ticket booking business process on official trips and conduct individual understanding from researchers. The results of this study were successfully made a prototype of the Internal Ticket System application called Business Travel by using a V-Shaped SDLC method. The prototype making method is more detailed because it has 4 rounds, namely requirements, specifications, high level design and low level unit design.
\end{abstract}

Keywords: Ticket, SDLC, V-Shaped, Prototype

\begin{abstract}
ABSTRAK
Kegiatan perjalanan dinas karyawan dalam suatu perusahaan memiliki peranan penting dalam mendukung operasional bisnis dan mengembangkan sayap usaha perusahaan, terutama bagi perusahaan-perusahaan besar yang memiliki banyak kantor cabang di berbagai pelosok daerah di Indonesia. Dengan makin banyaknya perjalanan dinas yang membutuhkan tiket perjalanan dinas, semakin dibutuhkan juga sistem yang dapat mengatur secara internal bagaimana tiket tersebut dibeli dan dibayar. Sistem tersebut dibutuhkan untuk mengurangi kegiatan perjalan dinas yang tidak dibutuhkan dan data yang valid untuk dibandingkan dengan data dari sistem pihak ketiga dalam hal pembayaran pemesanan tiket. Peneliti melakukan studi pustaka, wawancara, dan observasi. Studi pustaka dilakukan peneliti untuk menemukan konsep metodologi yang sesuai untuk melakukan pengembangan aplikasi Internal Ticketing System. Wawancara digunakan untuk meneliti masukan-masukan penting terhadap aplikasi Internal Ticketing System dari beberapa perusahaan yang memiliki kegiatan perjalanan dinas yang cukup intensif, agar sesuai dan berguna untuk nantinya dapat diimplementasikan pada lapangan, serta observasi bisnis diberdayakan oleh peneliti untuk melihat secara langsung proses bisnis pemesanan tiket dalam perjalan dinas dan melakukan pemahaman individu dari peneliti. Hasil dari penelitian ini adalah berhasilnya dibuat prototipe dari aplikasi Internal Ticketing System yang disebut dengan Business Trip dengan menggunakan metodologi SDLC V-Shaped. Dengan metode ini pembuatan prototipe jadi lebih detail karena memiliki 4 tahapan yaitu requirement, specification, high-level design dan unit design low level.
\end{abstract}

Kata Kunci: Tiket, SDLC, V-Shaped, Prototipe 


\section{PENDAHULUAN}

Software Development Life Cycle (SDLC) sebuah strategi dalam membuat atau merawat sebuah sistem aplikasi, dan Waterfall, Vee-Methodology, dan Rational Unified Process (RUP adalah jenis-jenis SDLC pada tradisional umumnya (Suryantara \& Andry, 2018).

Kegiatan perjalanan dinas karyawan dalam suatu perusahaan memiliki peranan penting dalam mendukung operasional bisnis dalam mengembangkan sayap usaha perusahaan. Tingginya intensitas kegiatan perjalanan dinas tentunya sangat memerlukan koordinasi yang tepat dan cepat antar kantor cabang perusahaan, dengan adanya penugasan dari atasan kepada karyawan untuk melakukan perjalanan dinas ke kantor cabang lainnya, karyawan harus membuat pemesanan tiket ke departemen yang bertugas untuk mengurus pembelian tiket pewasat perjalanan dinas.

Oleh karena itu, fenomena tersebut haruslah dapat dikontrol oleh perusahaan, dimulai dari bagaimana mengatur secara internal proses pembelian dan pembayaran tiket perjalanan dinas itu sendiri. Bisnis proses sendiri yang mendukung perjalanan dinas ini sudah dilakukan oleh perusahaan dan berguna mencapai nilai tambahan terkait pekerjaan, tetapi dalam hal pengembangan aplikasi yang mendukung tertutama masalah pembelian tiket masih belum dijangkau oleh perusahaan (Ivgantius \& Andry, 2019).

Tetapi, pada saat ini banyak perusahaan yang hanya bergantung kepada sistem yang disediakan oleh para travel agent, sehingga kemungkinan bisa saja terjadi pengelapan dana yang bermain antara para travel agent dan bagian internal dari perusahaan atau apabila sistem dari travel agent mempunyai kesalahan, perusahaan tidak memiliki data yang akurat. Melihat hal tersebut, peneliti melihat adanya celah yang dapat diatasi oleh perusahaan dengan membuat aplikasi yang mengontrol seluruh proses pembelian tiket perjalanan dinas tersebut.

Guna mendukung keinginan peneliti untuk membuat aplikasi Internal Ticketing System yang disebut Aplikasi Business Trip, maka diperlukan suatu metode SDLC (Systems Development Life Cycle) yang sesuai dalam mengembangkan aplikasi tersebut. Pemilihan metodologi ini merupakan salah satu aspek penting dalam proses perjalanan manajemen proyek, karena kesalahan pemilihan metodologi dapat menyebabkan kekeliruan ataupun kesalahan proses dalam pengembangan sistem atau perangkat lunak tersebut (Kumar, N., Zadgaonkar, A. S., \& Shukia, 2013).
Peneliti memilih menggunakan metode SDLC V-Shaped dikarenakan metode ini merupakan pengembangan dari metode SDLC Waterfall yang lebih difokuskan ke verifikasi dan validasi pada saat proses kebutuhan dan testing. Sehingga metode SDLC $V$-Shaped ini sangat cocok untuk digunakan sebagai metodologi pengembangan perangkat lunak yang tidak memiliki pengguna yang pasti dan kebutuhan yang spesifik dan digeneralkan yang kemungkinan dapat berubah terus-menurus atau ketidakpastian kebutuhan (Kute, S. S., \& Thorat, 2014).

\section{METODE PENELITIAN}

\section{Tahapan Penelitian}

Penelitian ini melakukan prosedur langkahlangkah yang digambarkan pada diagram alir dibawah ini:

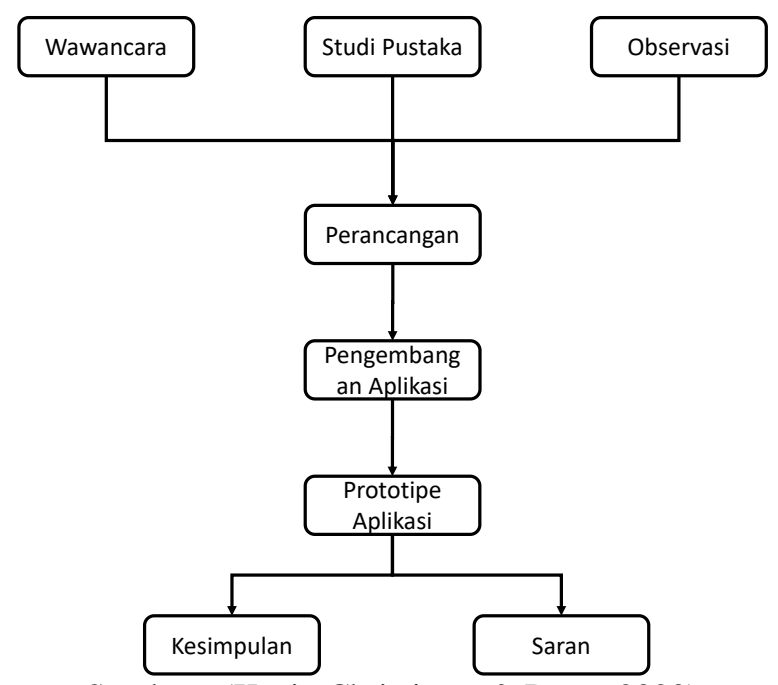

Sumber : (Kevin Christianto \& Deny, 2020)

Gambar 1. Langkah - Langkah Prosedur Penelitian

Namun demikian model-model itu dapat dikelompokkan berdasarkan sifatnya yaitu statis atau dinamis (Budiyantara et al., 2020). Jenis diagram itu antara lain:

1. Tahap pertama: peneliti melakukan 3 metode pengumpulan data yang digunakan untuk menyelesaikan penelitian ini, yaitu studi pustaka, wawancara dan observasi.

a. Metode studi pustaka: Mengumpulkan data dari berbagai jenis buku, jurnal, artikel dan literatur lainnya yang akan digunakan sebagai landasan teori.

b. Metode wawancara: Melakukan tanya jawab kepada pengguna salah satu 
perusahaan yang memiliki intensitas tinggi atau keperluan untuk perjalanan dinas.

c. Metode Observasi: Melakukan pengamatan yang dilakukan dengan mengunjungi perusahaan terkait yang diambil peneliti sebagai objek dan melihat cara kerja langsung bagaimana proses pembelian tiket perjalanan dinas tersebut.

2. Tahap kedua: peneliti mulai melakukan penelitian dengan analisis data berupa perancangan dengan bantuan metode seperti flowchart, UML dan ERD sebagai dasar perancangan aplikasi ini.

3. Tahap ketiga: peneliti melakukan pengkodean yang telah dirancangan pada tahap sebelumnya dengan menggunakan bahasa pemogramman PHP dan database MySQL.

4. Tahap keempat: peneliti melakukan proses prototipe pada objek penelitian dan menjalankan proses percobaan pada prototipe aplikasi, dan menentukan apakah aplikasi sudah sesuai dengan perancangan.

5. Tahap kelima: peneliti menutup penelitian ini dengan menarik kesimpulan dan saran dari hasil penelitian ini.

\section{Langkah Metode SDLC V-Shaped}

Berikut langkah - langkah SDLC V-Shaped (Balaji, S., \& Murugaiyan, 2012).

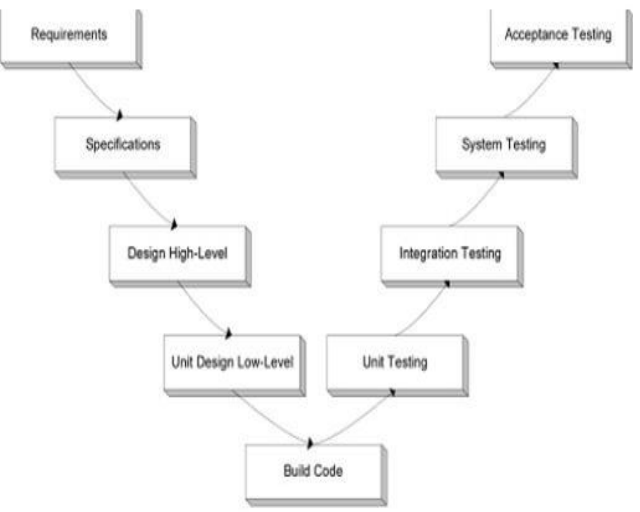

Sumber : (Kevin Christianto \& Deny, 2020)

Gambar 2. Langkah - Langkah SDLC V-Shaped Model

Penelitian ini melakukan pengembangan aplikasi menggunakan SDLC $V$-Shaped dengan detail penelitian:

1. Requirements: Proses requirements di manajemen proyek ini meliputi proses wawancara dan observasi proses bisnis Internal Ticketing System pada beberapa tempat dan user.
2. Specifications: Dalam proses ini spesifikasi secara keseluruhan dalam pembentukan infrastruktur dan Hardware penunjang dari kebutuhan user yang telah dikumpulkan pada proses requirements

3. Design High-Level: Desain di proses ini akan menggambarkan proses sistem secara garis besar pada luaran dari aplikasi.

4. Unit Design Low-Level: Setelah High-Level, lalu masuk kebagian pendetailan desain sebelum masuk kedalam proses development.

5. Build Code: Proses pengerjaan development dari aplikasi Business Trip.

6. Unit Testing: Skenario pengujian pada proses ini dibuatkan secara pararel saat low-level desain sedang dirancang juga dan dieksekusi setelah proses pengkodean selesai untuk beberapa lowlevel desain tersebut.

7. Integration Testing: Skenario pengujian pada proses ini dibuatkan secara pararel saat highlevel desain sedang dirancang juga dan dieksekusi setelah proses pengkodean lebih dari 1 proses selesai untuk diintegrasikan dari proses yang satu ke proses yang lain

8. System Testing: Skenario pengujian terproses saat gambaran secara keseluruhan sistem sudah tergambar oleh peneliti dan akan di eksekusi setelah seluruh proses pengkodean selesai dan siap untuk masuk ke final proses pengujian.

9. Acceptance Testing: Skenario pengujian dibuat saat kebutuhan user sudah ter-mapping dengan baik dan dituangkan dalam skenario yang user friendly agar dapat di uji oleh user untuk melihat apakah hasil yang diharapkan sesuai dengan kebutuhan yang dijabarkan diawal.

\section{HASIL DAN PEMBAHASAN}

\section{Requirement}

Pada step awal ini, peneliti akan melakukan proses pengumpulan fakta sebagai analisa kebutuhan pada pembuatan aplikasi. Metode analisa yang digunakan oleh peneliti adalah wawancara dan observasi dengan para calon pengguna atau orang yang merasa dibutuhkannya aplikasi Internal Ticketing System ini ini.

Proses wawancara yang dilakukan peneliti mengambil sampel dengan wawancara langsung ke pengguna yang berhubungan langsung dengan proses melakukan perjalanan dinas dalam sebuah perusahaan. Wawancara dilakukan ke satu pengguna utama agar peneliti dapat lebih fokus untuk memecahkan dari masalah yang ada. Rangkuman dari wawancara 
pengambilan analisa kebutuhan dapat dilihat dibawah ini:

1. Analisa sistem berjalan

Dalam sistem yang berjalan, seluruh proses perjalanan dinas dimulai dari pengguna membuat surat tugas yang nanti akan di setujui oleh atasan langsung pengguna. Dari awal tersebut, nanti akan dilanjutkan dalam bagian GA, di GA-lah seluruh proses terjadi, mulai dari pemesanan tiket (yang dilakukan ke pihak eksternal yaitu agen perjalanan), proses negosiasi, persetujuan atasan GA hingga proses pencairan tiket pesawat. Setelah tiket pesawat cair dan pengguna melakukan perjalanan dinas. Agen perjalanan biasanya mengirimkan excel hasil tiket-tiket yang sudah dipesan oleh perusahaan tiap akhir bulan, dan perusahaan melakukan pembayaran berdasarkan excel yang disediakan oleh agen perjalanan itu.

2. Analisa harapan pengguna terhadap sistem yang akan datang

Pada sistem akan datang, diharapkan semua proses dapat dicakup kedalam sistem, agar lebih terstruktur dan tertata rapih. Sehingga data yang dihasilkan oleh sistem bisa menjadi bahan pembanding terhadap nilai yang ditagihkan ke perusahaan oleh agen perjalanan tiap bulannya. Tetapi selain itu, pengguna tetap berharap masih ada proses yang manual tapi tetap dicatat dalam aplikasi seperti proses negosiasi atau proses perubahan jadwal tiket.

Dari hasil analisa diatas, dapat ditarik kesimpulan bahwa dibutuhkan sesuai yang terstruktur dan tercatat rapih untuk melakukan proses rekonsilisasi data dengan pihak eksternal. Sehingga ada 2 manfaat utama yaitu membuat proses prosedur perjalan dinas menjadi lebih baik dan memberikan proses rekonsilisasi dengan pihak external untuk proses pembayaran yang lebih terjamin untuk peruhsaan. Untuk visualisasi dari analisa diatas, peneliti membuatkan proses flowchart untuk masingmasing dari proses analisa diatas, yaitu:

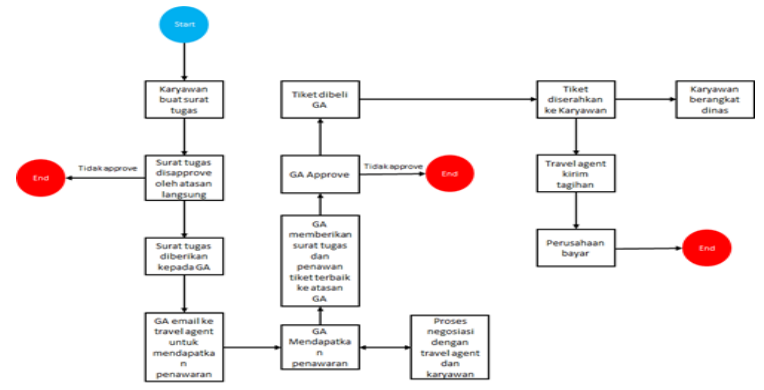

Sumber : (Kevin Christianto \& Deny, 2020)

Gambar 3. Analisa sistem berjalan
Dari hasil visualisasi diatas, peneliti melihat terdapat beberapa proses yang bisa dibuat lebih baik atau dibantu oleh sistem, seperti proses pengiriman email ke agen perjalanan bisa dilakukan secara sistem, pengumpulan tiket yang sudah dibeli, dan proses rekonsilisasi yang diperlukan untuk proses pembayaran. Oleh sebab itu, peneliti dapat membuat proses akan datang dari sistem tersebut dalam menggunakan sistem menjadi:

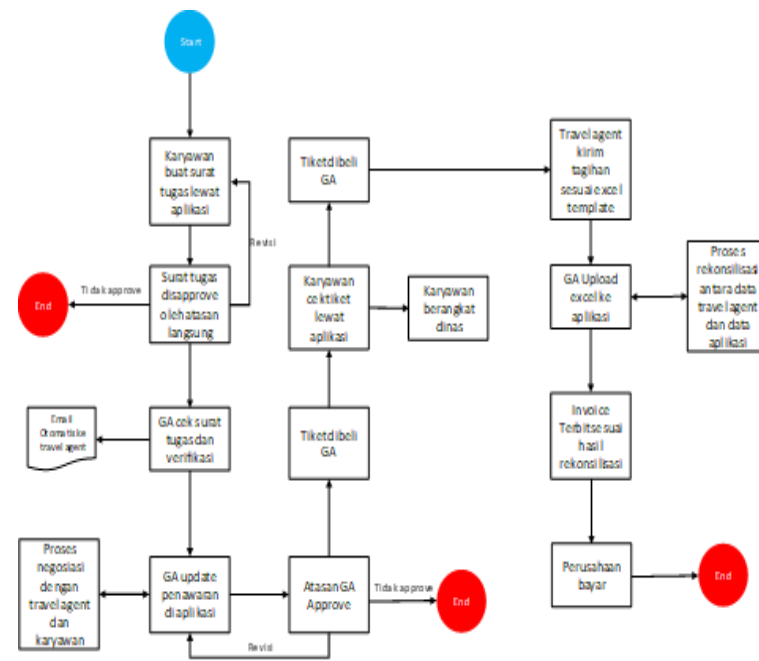

Sumber : (Kevin Christianto \& Deny, 2020)

Gambar 4. Analisa sistem akan datang

Flowchart diatas mengambarkan proses perjalan dinas yang telah menggunakan sistem yang dibuat oleh peneliti. Dengan adanya sistem yang diajukan peneliti maka dapat dilihat terdapat beberapa hal yang membantu pengguna serta tambahan proses yang bisa menjaga proses penyelewengan dana pembelian tiket dengan proses rekonsilisasi dalam aplikasi.

\section{Design High-Level}

Langkah selanjutnya adalah melakukan proses perancangan secara garis besar. Hal ini agar peneliti dapat melihat secara keseluruhan dari batasan atau ruang lingkup dari sistem yang akan dikembangkan. Dalam perancangan ini peneliti akan menggunakan tools berupa UML (Unified Modeling Language) yaitu use case diagram dan activity diagram. Selain UML, peneliti juga menggunakan konsep perancangan ERD (Entity Relationship Diagram) dalam menggambarkan struktur database yang nantinya akan dibuat. Peneliti menggunakan kedua tools tersebut karena keduanya merupakan tools yang paling terkenal dan masih yang paling ideal digunakan untuk pengembangan sistem berorientasi terhadap objek ini. 
Pertama-tama peneliti akan menggambarkan use case diagram, karena dengan use case diagram ini pengguna akan memahami secara simpel apa yang nanti akan pengguna lakukan saat sistem ini diimplementasikan. Berikut perancangan dari use case diagram tersebut:

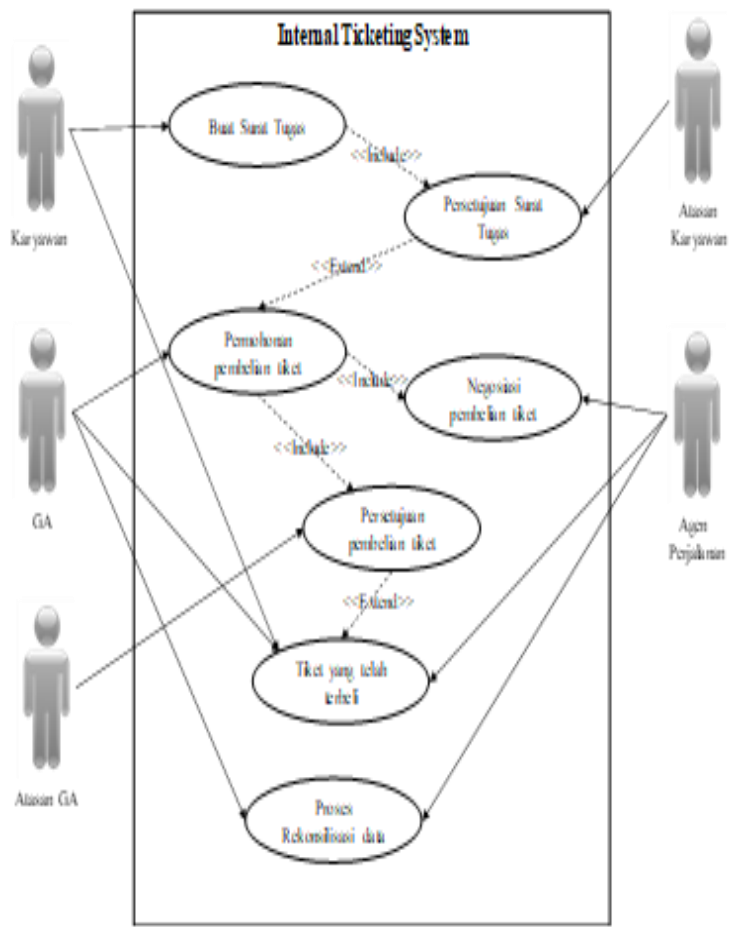

Sumber : (Kevin Christianto \& Deny, 2020) Gambar 5. Use case diagram

Dalam use case diatas, digambarkan nantinya dalam sistem ada 5 aktor, yaitu karyawan, atasan karyawan, GA, atasan GA dan agen perjalanan. Dimana aktor utamanya ada 3, yaitu karyawan, GA dan agen perjalanan. Dimana peran dalam aplikasi banyak perpusat di GA, tetapi awal dari proses tetap diajukan oleh karyawan. Dan dari use case diatas, dapat dilihat juga bahwa atasan hanya sebagai proses persetujuan saja untuk setiap inputan dari bawahannya. Dan di akhir proses terdapat proses rekonsiliasi yang menjadi fitur utama dalam hal mencegah hal penyelewengan dana saat pembayaran tiket-tiket yang telah digunakan oleh karyawan perusahaan.

Kedua peneliti juga merancang sistem ini menggunakan activity diagram, karena dengan activity diagram peneliti dapat melihat secara garis besar aktivitas-aktivitas apa yang ada dalam keseluruhan sistem yang akan dibangun. Dan berikut gambaran activity diagram yang dirancang oleh peneliti:

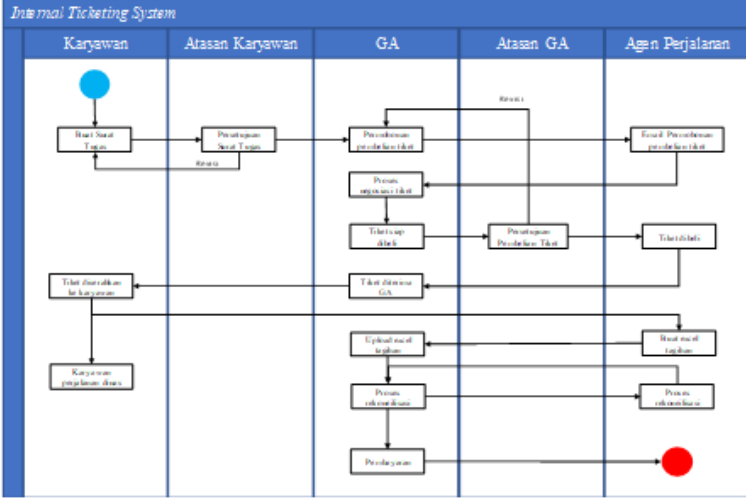

Sumber : (Kevin Christianto \& Deny, 2020) Gambar 6. Activity diagram

Dalam activity diagram diatas, dapat dibagi menjadi 3 aktivitas besar yaitu Pengajuan, proses tiket, hingga pembayaran tiket, yang penjelasannya dapat dilihat dibawah ini:

1. Langkah awal karyawan harus mengajukan surat tugas terlebih dahulu ke sistem

2. Lalu, surat tugas tersebut nantinya wajib melewati persetujuan dari atasan langsung karyawan.

3. Dan hanya surat tugas yang sudah disetujui oleh atasan langsung lah yang masuk ke dalam pekerjaan GA untuk diproses pemesanan tiketnya.

4. GA akan melihat surat tugas dan membuatkan pemesanan tiket berdasarkan surat tugas yang telah disetujui.

5. Setelah itu sistem akan secara otomatis mengirimkan email terkait tiket yang dibutuhkan oleh perusahaan ke agen perjalanan.

6. Lalu, akan ada proses negosiasi antara GA dan agen perjalanan diluar sistem untuk mendapatkan tiket yang pas untuk karyawan melakukan perjalanan dinas.

7. Setelah tiket siap untuk dibeli, maka GA akan mengajukan proses pembelian tiket ini untuk persetujuan dari atasan GA sebagai dasar untuk membeli tiket.

8. Tiket akan dibeli oleh agen perjalanan setelah atasan GA telah menyetujui permohonan yang diajukan GA.

9. Tiket yang sudah dibeli akan diberikan dari agen perjalanan ke GA, dan akan diterukan ke karyawan agar bisa melakukan perjalanan dinas.

10. Lalu, setiap akhir bulan agen perjalanan akan membuat excel tentang tiket-tiket yang sudah dibeli perusahaan untuk dibayar.

11. Excel tersebut akan diupload oleh GA ke dalam sistem dan melakukan proses rekonsilisasi data. 
12. Setelah proses rekonsiliasi selesai, invoice akan keluar dan agen perjalanan akan dibayar sesuai dengan nilai akhir dari proses rekonsilisasi.

Terakhir peneliti melakukan perncangan database yang direpresentasikan dengan ERD sebagai fondasi awal dibuatnya sistem. Dengan ERD ini peneliti dapat memetakan entitas-entitas dalam sistem dan hubungan tiap entitas tersebut. Dan berikut gambaran Entity Relationship Diagram (ERD) yang dirancang oleh peneliti:

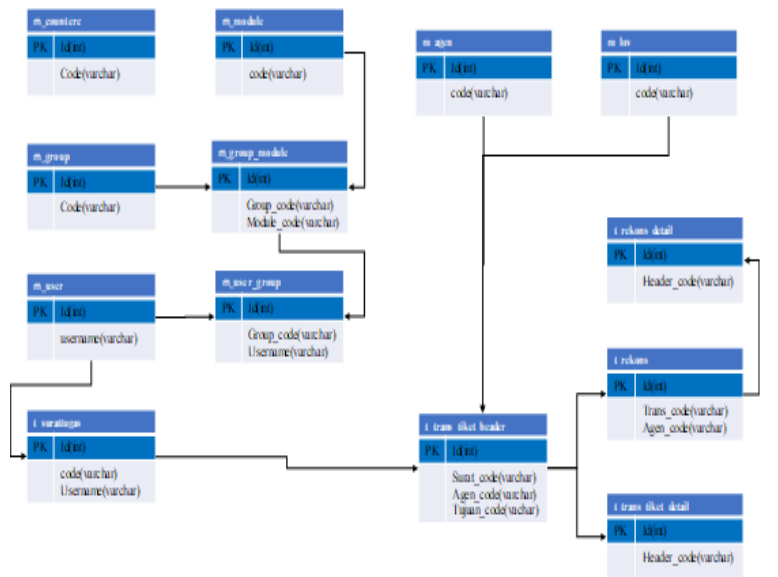

Sumber : (Kevin Christianto \& Deny, 2020) Gambar 7. ERD

Dalam entity relationship diagram diatas, dapat lihat bahwa total tabel database yang dibuat oleh peneliti berjumlah 13 dengan beberapa bagian dari tabel tersebut, seperti tabel untuk transaksi, master dan konfigurasi untuk aplikasi..

\section{Unit Design Low-Level}

Pada langkah ini peneliti coba menjelaskan lebih detail dari desain besar yang telah dibuat dilangkah sebelumnya. Desain mengikuti halaman login, master-master data dan transaksi. Berikut desain untuk login dan transaksi yang ada dalam aplikasi nantinya:

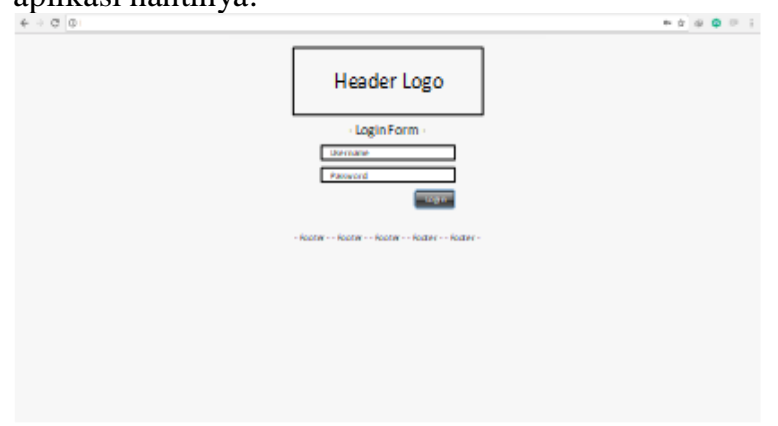

Sumber : (Kevin Christianto \& Deny, 2020)

Gambar 8. Halaman Login

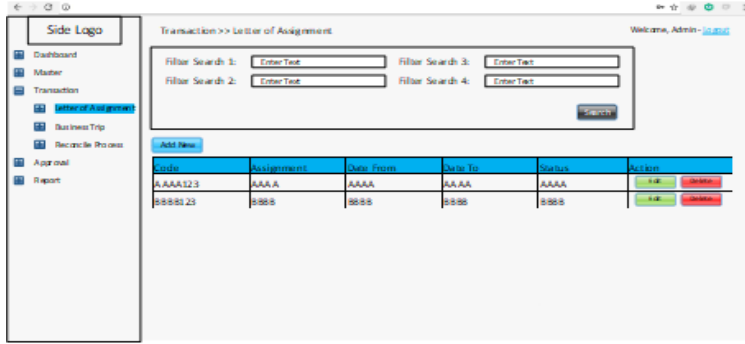

Sumber : (Kevin Christianto \& Deny, 2020)

Gambar 9 Halaman Grid Letter of Assignment

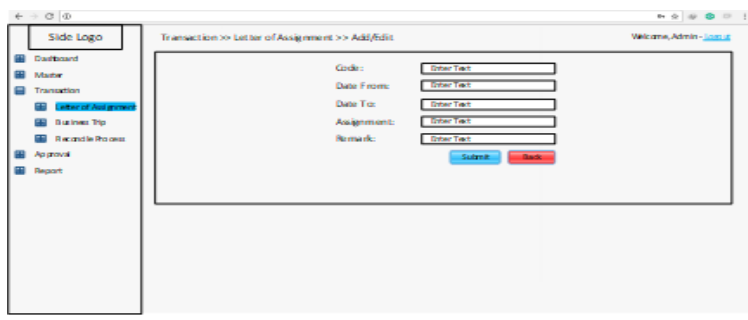

Sumber : (Kevin Christianto \& Deny, 2020)

Gambar 10. Halaman Add/Edit Letter of Assignment

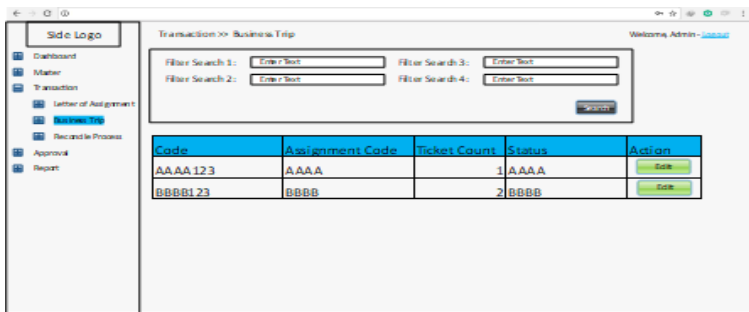

Sumber : (Kevin Christianto \& Deny, 2020)

Gambar 11. Halaman Grid Business Trips

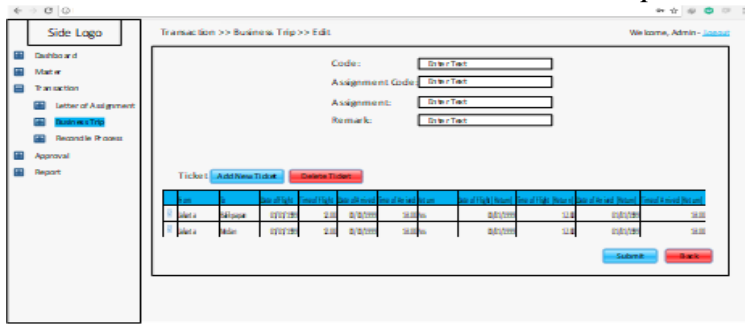

Sumber : (Kevin Christianto \& Deny, 2020)

Gambar 12. Halaman Add/Edit Business Trips

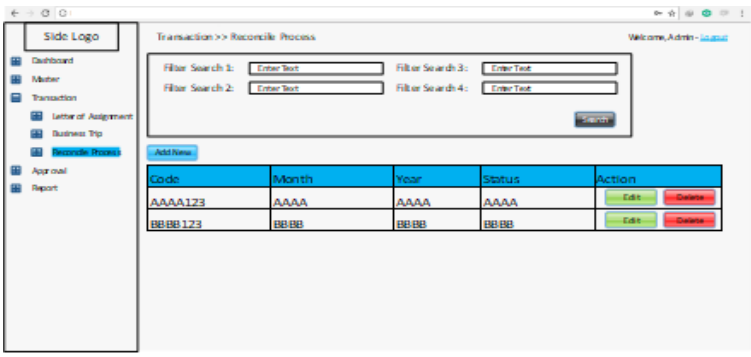

Sumber : (Kevin Christianto \& Deny, 2020)

Gambar 13. Halaman Grid Reconcile Process 

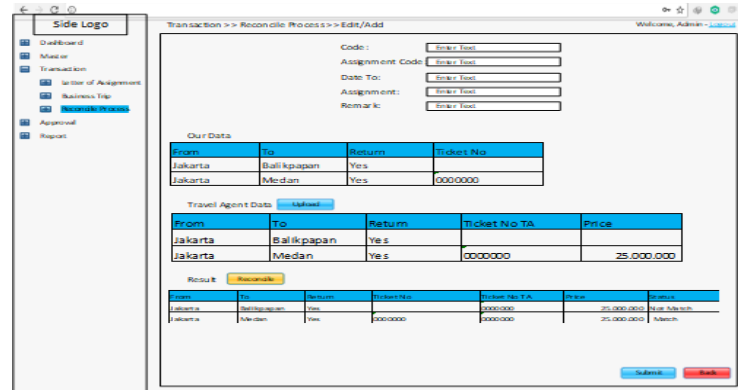

Sumber : (Kevin Christianto \& Deny, 2020)

Gambar 14. Halaman Add/Edit Reconcile Process

\section{Acceptance Testing}

Tabel 1. Bobot Alternatif Secara Keseluruhan

\begin{tabular}{|c|c|c|}
\hline Nama Skenario & Keterangan & $\begin{array}{c}\text { Hasil } \\
\text { Uji }\end{array}$ \\
\hline Uji Login & $\begin{array}{c}\text { Tampilan halaman login } \\
\text { dalam aplikasi }\end{array}$ & Sukses \\
\hline Uji Dashboard & $\begin{array}{c}\text { Tampilan halaman } \\
\text { Dashboard dalam } \\
\text { aplikasi }\end{array}$ & Sukses \\
\hline $\begin{array}{l}\text { Uji Master User - } \\
\text { Grid }\end{array}$ & $\begin{array}{c}\text { Tampilan halaman } \\
\text { Master User - Grid } \\
\text { dalam aplikasi } \\
\end{array}$ & Sukses \\
\hline $\begin{array}{l}\text { Uji Master User - } \\
\text { Edit }\end{array}$ & $\begin{array}{c}\text { Tampilan halaman } \\
\text { Master User - Edit } \\
\text { dalam aplikasi }\end{array}$ & Sukses \\
\hline $\begin{array}{c}\text { Uji Master Group } \\
\text { - Grid }\end{array}$ & $\begin{array}{l}\text { Tampilan halaman } \\
\text { Master Group - Grid } \\
\text { dalam aplikasi }\end{array}$ & Sukses \\
\hline $\begin{array}{c}\text { Uji Master Group } \\
\text { - Edit }\end{array}$ & $\begin{array}{c}\text { Tampilan halaman } \\
\text { Master Group - Edit } \\
\text { dalam aplikasi }\end{array}$ & Sukses \\
\hline $\begin{array}{l}\text { Uji Master LoV- } \\
\text { Grid }\end{array}$ & $\begin{array}{l}\text { Tampilan halaman } \\
\text { Master LoV - Grid } \\
\text { dalam aplikasi }\end{array}$ & Sukses \\
\hline $\begin{array}{c}\text { Uji Master LoV- } \\
\text { Edit }\end{array}$ & $\begin{array}{l}\text { Tampilan halaman } \\
\text { Master LoV - Edit } \\
\text { dalam aplikasi }\end{array}$ & Sukses \\
\hline $\begin{array}{l}\text { Uji Master Travel } \\
\text { Agent - Grid }\end{array}$ & $\begin{array}{c}\text { Tampilan halaman } \\
\text { Master Travel Agent - } \\
\text { Grid dalam aplikasi }\end{array}$ & Sukses \\
\hline $\begin{array}{c}\text { Uji Master Travel } \\
\text { Agent - Edit }\end{array}$ & $\begin{array}{c}\text { Tampilan halaman } \\
\text { Master Travel Agent - } \\
\text { Edit dalam aplikasi }\end{array}$ & Sukses \\
\hline $\begin{array}{c}\text { Uji Transaction } \\
\text { Letter of } \\
\text { Assignment - Grid }\end{array}$ & $\begin{array}{l}\text { Tampilan halaman } \\
\text { Transaction Letter of } \\
\text { Assignment - Grid } \\
\text { dalam aplikasi }\end{array}$ & Sukses \\
\hline $\begin{array}{c}\text { Uji Transaction } \\
\text { Letter of } \\
\text { Assignment - Edit }\end{array}$ & $\begin{array}{l}\text { Tampilan halaman } \\
\text { Letter of Assignment - } \\
\text { Edit dalam aplikasi }\end{array}$ & Sukses \\
\hline $\begin{array}{l}\text { Uji Transaction } \\
\text { Business Trip - } \\
\text { Grid }\end{array}$ & $\begin{array}{c}\text { Tampilan halaman } \\
\text { Transaction Business } \\
\text { Trip - Grid dalam } \\
\text { aplikasi } \\
\end{array}$ & Sukses \\
\hline
\end{tabular}

\begin{tabular}{|c|c|c|}
\hline $\begin{array}{c}\text { Uji Transaction } \\
\text { Business Trip - } \\
\text { Edit }\end{array}$ & $\begin{array}{c}\text { Tampilan halaman } \\
\text { Transaction Business } \\
\text { Trip - Edit dalam } \\
\text { aplikasi } \\
\end{array}$ & Sukses \\
\hline $\begin{array}{c}\text { Uji Transaction } \\
\text { Reconcile Process } \\
\text { - Grid }\end{array}$ & $\begin{array}{c}\text { Tampilan halaman } \\
\text { Transaction Reconcile } \\
\text { Process - Grid dalam } \\
\text { aplikasi }\end{array}$ & Sukses \\
\hline $\begin{array}{c}\text { Uji Transaction } \\
\text { Reconcile Process } \\
\text { - Edit }\end{array}$ & $\begin{array}{c}\text { Tampilan halaman } \\
\text { Transaction Reconcile } \\
\text { Process - Edit dalam } \\
\text { aplikasi }\end{array}$ & Sukses \\
\hline $\begin{array}{c}\text { Uji Approval } \\
\text { Letter of } \\
\text { Assignment-Grid }\end{array}$ & $\begin{array}{l}\text { Tampilan halaman } \\
\text { Approval Letter of } \\
\text { Assignment - Grid } \\
\text { dalam aplikasi }\end{array}$ & Sukses \\
\hline $\begin{array}{c}\text { Uji Approval } \\
\text { Letter of } \\
\text { Assignment - Edit }\end{array}$ & $\begin{array}{c}\text { Tampilan halaman } \\
\text { Approval Letter of } \\
\text { Assignment }- \text { Edit dalam } \\
\text { aplikasi }\end{array}$ & Sukses \\
\hline $\begin{array}{c}\text { Uji Approval } \\
\text { Business Trip - } \\
\text { Grid }\end{array}$ & $\begin{array}{l}\text { Tampilan halaman } \\
\text { Approval Business Trip } \\
\text { - Grid dalam aplikasi }\end{array}$ & Sukses \\
\hline $\begin{array}{c}\text { Uji Approval } \\
\text { Business Trip - } \\
\text { Edit }\end{array}$ & $\begin{array}{l}\text { Tampilan halaman } \\
\text { Approval Business Trip } \\
\text { - Edit dalam aplikasi }\end{array}$ & Sukses \\
\hline
\end{tabular}

Sumber : (Kevin Christianto \& Deny, 2020)

Dari tabel diatas pengguna menguji total dari 20 skenario penerimaan dari design aplikasi Business Trip. Dan dari 20 skenario pengujian yang telah dibuat peneliti, peneliti mendapatkan angka $100 \%$ pengujian sukses. Oleh karena itu, 20 skenario penerimaan deisng bisnis yang berjalan pada aplikasi Business Trip dan telah sukses terlewati yang berarti design bisnis yang telah berjalan dan digunakan oleh pengguna sudah bisa diakomodir oleh aplikasi Business Trip.

\section{Implementation}

Setelah melewati serangkaian proses metode $V$-Shaped, maka sistem aplikasi ini sudah bisa untuk diimplementasikan dalam bentuk prototipe sebagai tahap awal untuk pengembangan sistem secara garis besarnya. Berikut gambaran hasil prototipe dari Aplikasi Business Trip ini.

Sumber : (Kevin Christianto \& Deny, 2020) Gambar 15. Hasil Prototipe Login 

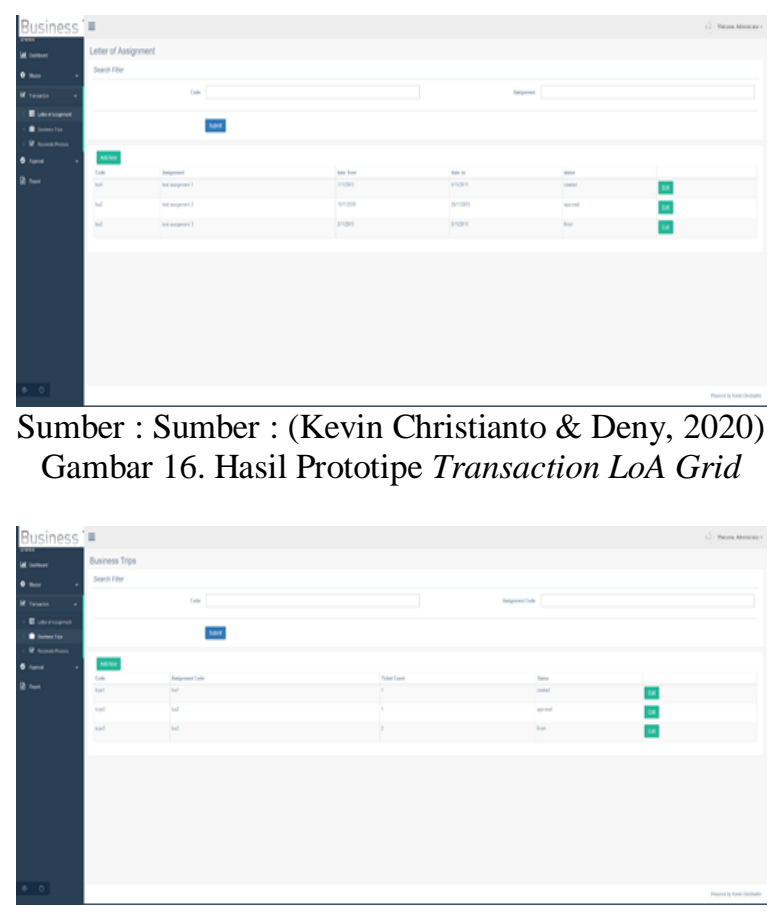

Sumber : Sumber : (Kevin Christianto \& Deny, 2020)

Gambar 17. Hasil Prototipe Transaction Business Trip Grid

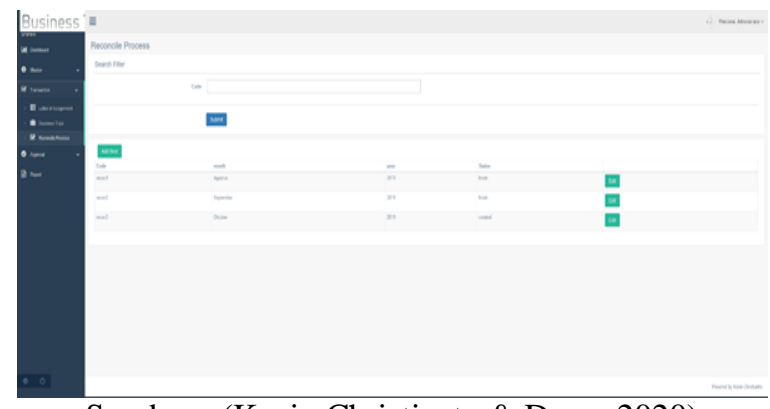

Sumber : (Kevin Christianto \& Deny, 2020)

Gambar 18. Hasil Prototipe Transaction Reconcile Grid

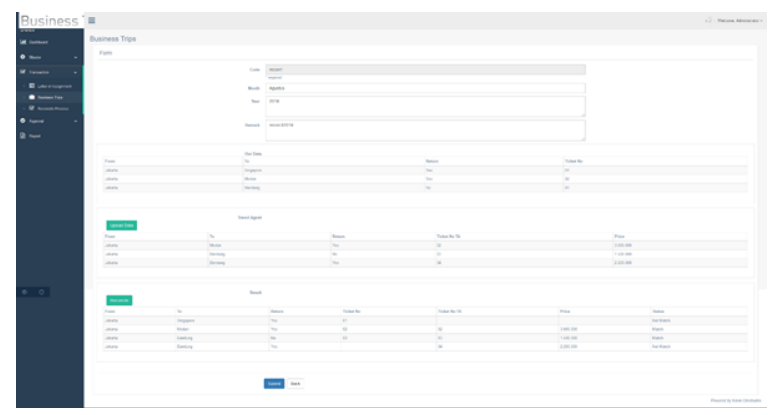

Sumber : (Kevin Christianto \& Deny, 2020)

Gambar 19. Hasil Prototipe Transaction Reconcile Edit

\section{KESIMPULAN}

Berdasarkan tujuan penelitian dan hasil penelitian di atas maka dapat disimpulkan beberapa hal berikut ini:

Dengan metode $V$-shaped peneliti dapat prototipe sistem aplikasi Business Trip yang support untuk proses rekonsilisasi untuk menghindari pengelapan dana. Metode $V$-shaped sendiri dalam proses penelitian dapat disimpulkan oleh peneliti bahwa metode ini lebih detail daripada metode waterfall, meskipun kedua metode tersebut sering disamakan, tetapi dalam pembuatan prototipe ada beberapa proses yang tidak dilalui dalam penelitian ini. Dan dalam proses pengumpulan analisa kebutuhan metode $V$-shaped lebih detail dengan pembagian proses menjadi 4 tahapan yaitu requirement, specification, high-level design dan unit design low level. Dengan tahapan tersebut peneliti berkesimpulan menghasilkan pengembangan prototipe yang meningkat dan lebih detail.

\section{DAFTAR PUSTAKA}

Agus Budiyantara, Irwansyah, Egi Prengki, P. A. P. (2020). Komparasi Algoritma Decision Tree, Naive Bayes Dan K-Nearest Neighbor Untuk Memprediksi Mahasiswa Lulus Tepat Waktu.

Balaji, S., \& Murugaiyan, M. S. (2012). Waterfall VModel Vs Agile: A Comparative Study on SDLC. International Journal of Information Technology and Business Management.

Ivgantius, T. Z., \& Andry, J. F. (2019). Development of Warehouse Management System Using Extreme Programming. 3(October), 39-46.

Kevin Christianto, \& Deny. (2020). Mendeteksi Pengelapan Dana Perjalanan Dinas Dengan Aplikasi Internal Ticketing System.

Kumar, N., Zadgaonkar, A. S., \& Shukia, A. (2013). Evolving a New Software Development Life Cycle Model SDLC-2013 with Client Satisfaction. International Journal of Soft Computing and Engineering (IJSCE).

Kute, S. S., \& Thorat, S. D. (2014). A Review on Various Software Development Life Cycle. International Journal of Research in Computer and Communication Technology (IJRCCT).

Suryantara, I. G. N., \& Andry, J. F. (2018). Development of Medical Record With Extreme Programming SDLC. International Journal of New Media Technology, 5(1), 47-53. https://doi.org/10.31937/ijnmt.v5i1.706 